\title{
La poesía de Palma ante el monumento del general San Martín el 28 de julio de 1890: la autocensura peruana y la protesta chilena
}

\author{
Arnaldo Mera \\ Pontificia Universidad Católica del Perú \\ arnaldo_mera@hotmail.com \\ Lima-Perú
}

\section{Resumen}

El presente artículo busca ahondar en un aspecto poco conocido del patriotismo de nuestro insigne tradicionista, en circunstancias de profunda congoja y dolor, como acaeció en nuestra capital días después de las exequias solemnes a los héroes de la Guerra del Pacífico y de las que Palma también fue víctima al perder en el incendio del pueblo de Miraflores su valiosa biblioteca. Dedicarle unas líneas en su poema al vencedor de la reciente guerra fue un acto de noble patriotismo cuando aún nuestro país sufría por los compatriotas inmolados en dicha gesta.

Palabras clave: poesía, Palma, General San Martín, Guerra del Pacífico

\section{Abstract:}

This article seeks to delve into a little-known aspect of the patriotism of our illustrious traditionalist, during circumstances of deep sorrow and pain, as happened in Lima days after the solemn funeral of the heroes of the War of the Pacific, Palma being also a victim when he lost his valuable library in the fire of Miraflores. To dedicate a few lines in his poem to the victor of the recent war was an act of noble patriotism when our country still suffered for the fellow countrymen immolated in that feat.

Keywords: Poetry, Palma, General San Martin, War of the Pacific 
Arnaldo Mera Ávalos (Perú): Bachiller en Historia y derecho, Licenciado con mención en Historia por la Pontificia Universidad Católica del Perú con la tesis "Las Pulperías en Lima ante el impacto de las reformas borbónicas" (2014), y donde cursó estudios de maestría en Historia y derecho Constitucional. Es Miembro asociado del Instituto Riva Agüero y Miembro de número del Instituto Ricardo Palma. Ha publicado "Ecuador y Perú: espacios regionales del siglo XIX"; "Pulperas, chinganeras y chicheras en la Lima republicana (1830-1860)"; "La armas del rey de España en sus dominios del Perú (1532-1824)"; "Cronología de Carlos A. Romero", entre otros artículos de historia del Perú, siglos XVIII y XIX. 


\section{El Perú de 1890}

Es importante recordar que el Perú en aquel año había firmado, el 8 de enero, en Santiago de Chile, el protocolo Elías-Castellón en el cual nuestro país negaba los vínculos del gobierno chileno con la deuda peruana sobre el guano. En abril se apresó al candidato presidencial Nicolás de Piérola y se clausuró el diario demócrata El País; se celebraron elecciones presidenciales y resultó ganador el coronel Remigio Morales Bermúdez y entre el 15 y 16 de julio se declaró duelo nacional para honrar a los héroes de la Guerra con Chile. Los restos del contralmirante Miguel Grau, llegaron al Callao, así como los de los combatientes de Huamachuco, Tacna y Arica, Tarapacá, San Francisco (Mera, 2006, p. 454). Este último hecho debió de conmover a la población capitalina y por ende motivar a Palma para redactar la poesía que leería ante el monumento al General San Martín.

\section{La lectura de la poesía en la ceremonia del 28 de julio de 1890}

Nos dice el colega sanmarquino y palmista, Pérez Garay en su libro Liberalismo Criollo:

Fiel a su fama de provocador, Palma asistió, el 28 de julio de 1890, a una ceremonia oficial en donde se hacía colocación de la primera piedra para el levantamiento del monumento del libertador San Martín. Después del discurso del ministro de Guerra, el presidente de la República y el ministro plenipotenciario argentino, Palma pidió la palabra y recitó unos versos a la memoria del libertador (2015, pp. 28-290).

Al respecto, ahonda Pérez Garay al señalarnos en la nota numero 35 a pie de página, citando una carta sin fecha ni ciudad de origen, dirigida a Luis Benjamín Cisneros en la cual le escribió: "Por teléfono pregunté al ministro Irigoyen si me sería permitido hacer uso de la palabra en la ceremonia del 28 y me contestó afirmativamente" [p. 290] 


\section{El reclamo chileno del 29 de julio}

Continúa diciéndonos Pérez Garay, citando al propio Palma en carta cursada el 31 de julio a Francisco Sosa, que:

La lectura de estos versos produjo la molestia y el disgusto del ministro plenipotenciario chileno, quien tras intensas gestiones, consiguió que se ordenara la no publicación de estos a través de la prensa. El día 29 de julio, el ministro de Chile envió un oficio al ministerio de Relaciones Exteriores, exigiendo en ella un gesto de desagravio. La respuesta del Gobierno fue inmediata y consideró que las palabras de Palma eran las de un literato y no las de un empleado público (2015, p. 290).

Al respecto, El Comercio publicó el martes 29 de julio de 1890 “con relación a los leídos por este literato nacional en la solemne ceremonia de ayer, con motivo de la colocación de la primera Piedra de la estatua de San Martín, nos dirige dicho señor Palma, la siguiente esquela":

Señor Director:

Señor y amigo

Feos o bonitos a ningún padre le gusta que sus hijos después de nacidos, sean mutilados. "El Nacional" de anoche publica la composición poética que en homenaje a San Martin, leí el día 28 suprimiendo dos redondillas, supresión que daña fondo y forma del trabajo literario, y que yo he estado muy lejos de autorizar.

Agradeciendo a U. que se digne dar a luz estas líneas, quedo. Muy suyo amigo afectísimo

Ricardo Palma ${ }^{1}$

1 El Comercio, Lima, martes 29 de julio de 1890, $N^{\circ} 17,166$, p. 1. 
El ministro chileno Álamos González en una comunicación al ministro de relaciones exteriores de su país del 30 de julio de 1890, le informó de la autocensura peruana en lo que respecta a la declamación y publicación del poema del tradicionista por parte de las máximas autoridades nacionales:

Tanto el Excmo. señor Presidente de la República como sus Ministros i los hombres más notables del Perú, que se encontraban presentes en aquel acto, dejaron ver, desde el primer momento el desagrado que les causó aquella inesperada manifestación; i, pocos momentos después, cuando fui a palacio con los demás miembros del Cuerpo Diplomático, para saludar al Jefe de Estado en el día solemne del aniversario de la independencia peruana, el Excmo. Señor Cáceres, todos los miembros de su Gabinete i los altos dignatarios de la Nación se empeñaron en asegurarme que el señor Palma no había intervenido oficialmente en aquel acto; que su conducta había sido severamente criticada por todos, I que ya se había solicitado I obtenido de los editores de diario que no publicaran en sus columnas aquellas imputaciones².

Resulta interesante que el propio ministro chileno exponga:

Pero a pesar de la espontaneidad de las manifestaciones i de las explicaciones de las autoridades peruanas i del empeño que mostraron en que no tuvieran resonancia aquellos impropios desahogos, no he querido darme por satisfecho con las explicaciones verbales ${ }^{3}$.

2 Archivo del Ministerio de Relaciones Exteriores del Perú (AMREP), Sección Legación del Perú en Chile 5-4 del 4 de setiembre de 1890 fl. 11 r.

3 Id. 
El ministro chileno Benicio Álamos González para justificar el envío de la nota aquella tarde del 28 de julio de 1890 , según lo expuesto en la misma nota cursada al ministro de Relaciones Exteriores de su país, argumentó lo siguiente:

El hecho de que el propósito de ofender a Chile hubiese ocurrido en un acto oficial; la circunstancia de que las imputaciones calumniosas las hubiera vertido un empleado de la nación peruana; i la profunda ingratitud que había en lanzar tales injurias, justamente cuando se trataba de inmortalizar en una estatua al jeneral(sic) en jefe de la expedición libertadora que envió Chile para iniciar la independencia del Perú, me decidieron a pasar la nota $[\ldots]$ "4.

Así el gobierno peruano recibió al poco tiempo de acabar el saludo por las fiestas patrias nacionales la nota número 100 de su legación, en la que expuso lo siguiente:

Señor Ministro: Creo de mi deber llamar la atención del gobierno de V. E. a los términos ofensivos a Chile empleados por uno de los oradores que tomaron parte en la fiesta oficial que tuvo lugar en la plaza del Teatro, [...] Prescindiendo de la poca conveniencia que había en aprovechar un acto oficial al que se invitó al Cuerpo Diplomático i a la Legación de Chile, para dar lugar a odiosos desahogos, no puedo tampoco dejar de extrañarme de la injusticia con que se ha procedido pretendiendo ultrajar al pueblo chileno, justamente en una manifestación que lo hacía acreedor a la gratitud del pueblo peruano. [...] Bien sé, por las espontaneas explicaciones privadas que se me han dado que el Excmo. señor Presidente de la República, V. E. sus colegas de Gabinete i muchos peruanos respetables i distinguidos han sido los primeros en reprobar aquella manifestación tan estemporanea(sic)

4 Id. 
como antipatriótica. Pero como el propósito de ofender fue público como tuvo lugar en un acto oficial i como la defensa fue hecha por un empleado al servicio de la nación peruana i que formaba parte del cortejo presidencial, creo de mi deber exigir una desautorización explícita, de lo sucedido, reservándole a mi gobierno el pedir una satisfacción distinta si lo estimare conveniente ${ }^{5}$.

\section{La autocensura y disculpa peruana}

La autocensura se llevó a cabo como bien lo acotó Palma, ya que se publicó su poesía de manera incompleta en la edición de El Nacional del lunes 28 de julio de 1890, número 67046 página 2 y el ministerio de Relaciones Exteriores a través de la dirección general le remitió el siguiente oficio al Director de la Biblioteca Nacional don Ricardo Palma:

S.E. el Presidente de la República oyó con profundo desagrado las palabras que respecto de la República de Chile, pronunció US. En la ceremonia de la colocación de la primera piedra del monumento que va a erigirse al general San Martin. No creía S.E. cuando concedió su venia para que US. hablara, no obstante de que su discurso no estaba designado en el programa que llevara US. su indiscreción al punto de turbar la armonía de la manifestación con espresiones(sic) destinadas a herir a una nación con la que estamos en paz i cuyo representante se hallaba, además presente por invitación del Gobierno; ni estima una prueba de patriotismo la vehemencia e inoportunidad con que US. relacionó hechos tan lejanos como los de la historia de San Martín, con los de la última Guerra. El carácter que US. reviste de jefe de un establecimiento público agrava,

5 Id.

6 El Nacional, Lima, lunes 28 de julio de 1890, Número 6704, p. 2. 
por otra parte, la falta que el Gobierno está en el caso de reprimir, en guarda de los respetos que se dispensan entre si las naciones cultas $[\ldots]^{7}$.

Esta comunicación fue firmada por José Galindo y dio su conformidad el oficial mayor del ministerio Carlos Wiesse y la respuesta oficial del gobierno peruano la firmó nuestro ministro de Relaciones Exteriores, fue remitida el 30 de julio de 1890 a don Benicio Álamos González, Enviado Extraordinario i Ministro Plenipotenciario de la República de Chile en los siguientes términos:

Señor: Tengo el honor de avisar recibo a V. E. de la nota fecha 28 del presente mes, que llegó a mis manos en la noche de ayer, en que V.E. se sirve llamar mi atención sobre los términos ofensivos a Chile empleados por uno de los oradores que tomaron parte en la ceremonia de la colocación de la primera piedra del monumento que va a erigirse al general San Martin, I pedirme una explícita desautorización de ellos. S.E. el Presidente de la República el infrascrito tuvieron ocasión de manifestar a V. E. pocas horas después de la ceremonia que el aludido discurso no estaba considerado en el programa; que al conceder su venia para que se pronunciara, no pudieron suponer que un empleado público se propusiese ofender a una nación con la cual el Perú se encuentra en paz I cuyo representante a invitación del Gobierno, honraba con su presencia esa fiesta eminentemente Americana; que habían escuchado con el más profundo desagrado las frases ofensivas que V.E. se queja con justicia; I que habían ordenado que por el Ministerio respectivo se manifestara al director de la Biblioteca Nacional la reprobación que su conducta había merecido del Gobierno. Estas declaraciones hechas como lo fueron, con la lealtad con que el Gobierno cumple los

7 AMREP Sección Legación de Perú en Chile 5-4 fl. 12r. 
deberes que la Amistad I la cortesía le imponen para con Chile i demás naciones, les reitero ahora, asegurando para satisfacción de V.E. i de su Gobierno que se ha dirigido el oficio cuya copia se servirá V.E. encontrar adjunta $[\ldots]^{8}$.

\section{La publicación de los versos suprimidos: octubre de 1890}

Las disculpas del gobierno peruano no pudieron evitar que los versos aparecieran "en los periódicos de Mejico (sic), y repúblicas del Plata y de Colombia, cuyas prensas al comentar el incidente diplomático hallaron merecedora de crítica la susceptibilidad del ministro chileno"9.

Será recién tres meses después; en el mes de octubre de 1890 a raíz de la publicación de un folleto que incluyó el poema de Palma completo de tres páginas y un poema chileno de réplica de diez páginas; por faltarle la carátula o portada, no sabemos realmente el título del mismo y también desconocemos el nombre de los editores de aquel ; pero gracias a ellos se pudo dar a conocer la poesía completa (anexo al presente artículo) con los versos que suprimió El Nacional; los cuales fueron los siguientes:

$$
\begin{aligned}
& \text { Y resucitara, asave, } \\
& \text { Con insidia antes no vista, } \\
& \text { El derecho de conquista } \\
& \text { En el siglo diecinueve }{ }^{10}
\end{aligned}
$$

Los editores de la poesía completa de nuestro tradicionista consideraron infundadas las exigencias del ministro chileno y la actuación de la cancillería peruana por las siguientes cinco razones:

\footnotetext{
8 Id.,

9 Publicación de octubre de 1890 de A San Martin, homenaje de un soldado de la patria vieja folleto s/c de 16 páginas lo transcrito se encuentra en la p. 2. y firmado por los editores (de quienes no sabemos quiénes fueron)

10 Id., p.4.
} 
1.- Porque nunca fue la poesía lenguaje oficial, 2.- Porque en el programa del Gobierno no estaba consignado que el señor Palma hablaría, 3.- Porque a la personalidad literaria del poeta no se podía ni debía negar el hacer uso de la palabra, 4.- Porque al hablar, no lo hizo en su carácter de empleado público, 5.- Porque no hay derecho para amordazar la expresión del sentimiento patriótico en los vencidos ${ }^{11}$.

Un mes antes el Diario Oficial chileno publicó el 3 de setiembre las notas enviadas a nuestro gobierno y a su gobierno por Benicio Álamos Gonzales, la respuesta peruana e inclusive el adjunto a la misma por lo cual todos en Chile se enteraron de la amonestación de parte del gobierno del general Cáceres a nuestro insigne tradicionista. Carlos Elías, de la Legación peruana en Santiago remitió los impresos de las mismas al día siguiente pero llegaron cuando ya era primer mandatario del país el general Remigio Morales Bermúdez; quien había asumido el mando el 10 de Agosto de 1890 [Mera:2006:454]. Finalmente, nos dirá Pérez Garay citando la correspondencia entre Palma y Sosa, del 31 de julio de 1890:

A pesar de los esfuerzos del ministro chileno ante su gobierno y el nuestro. Palma pudo salir bien librado de este incidente, gracias a la ayuda de su amigo Manuel Irigoyen, ministro de Relaciones Exteriores. Por cierto, Palma logró reconocer su carácter polémico y provocador en este incidente. Sobre ello afirmó: "hay hombres que tienen la mala estrella de levantar polvareda y yo soy uno de ellos (2015, p. 290).

Fue una muestra de patriotismo en una época de desánimo, dolor y tristeza por los recuerdos que conllevó el traslado a Lima desde Chile de los restos de todos los héroes de la Guerra de expansión del ahora vecino país del sur.

11 Id., p.l. 


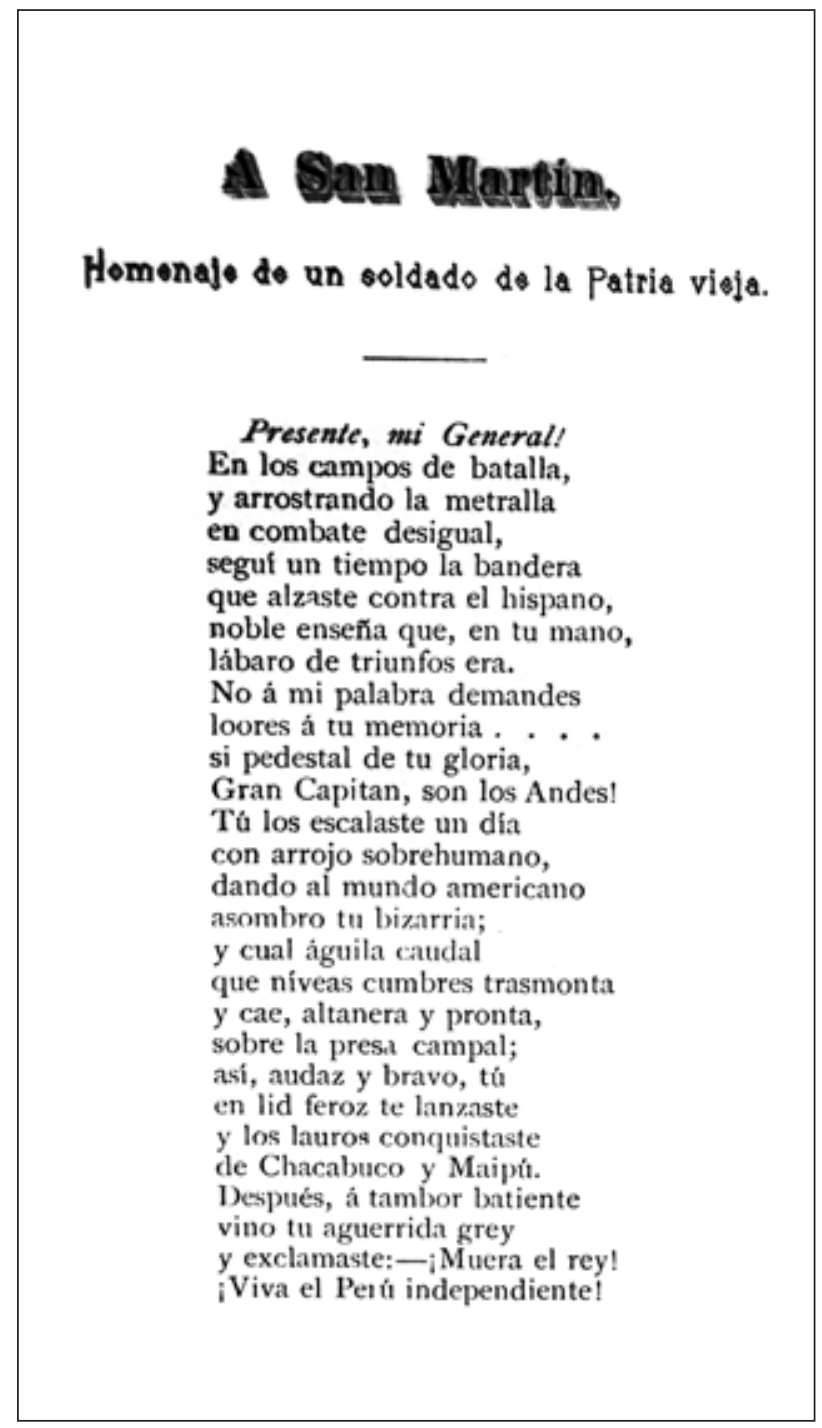




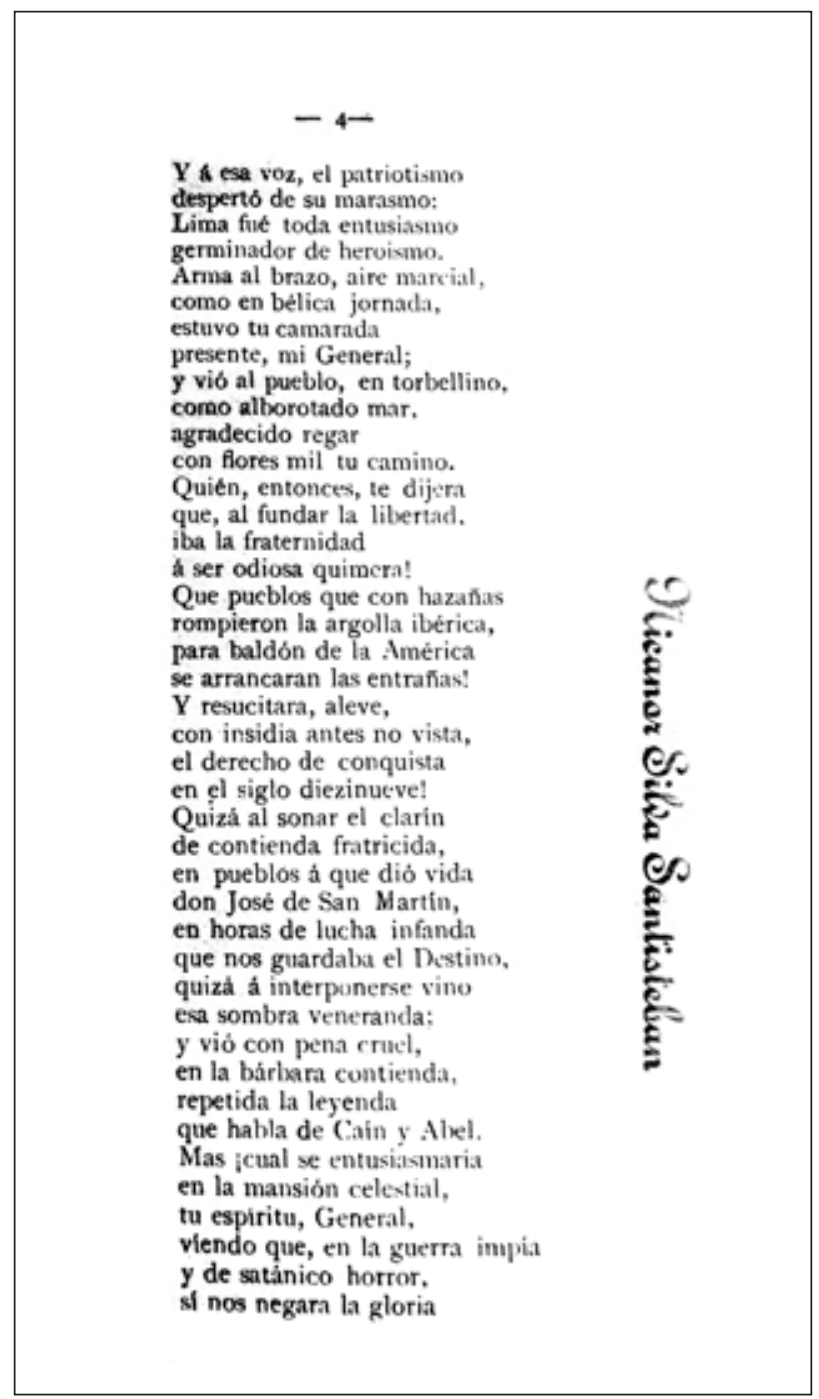




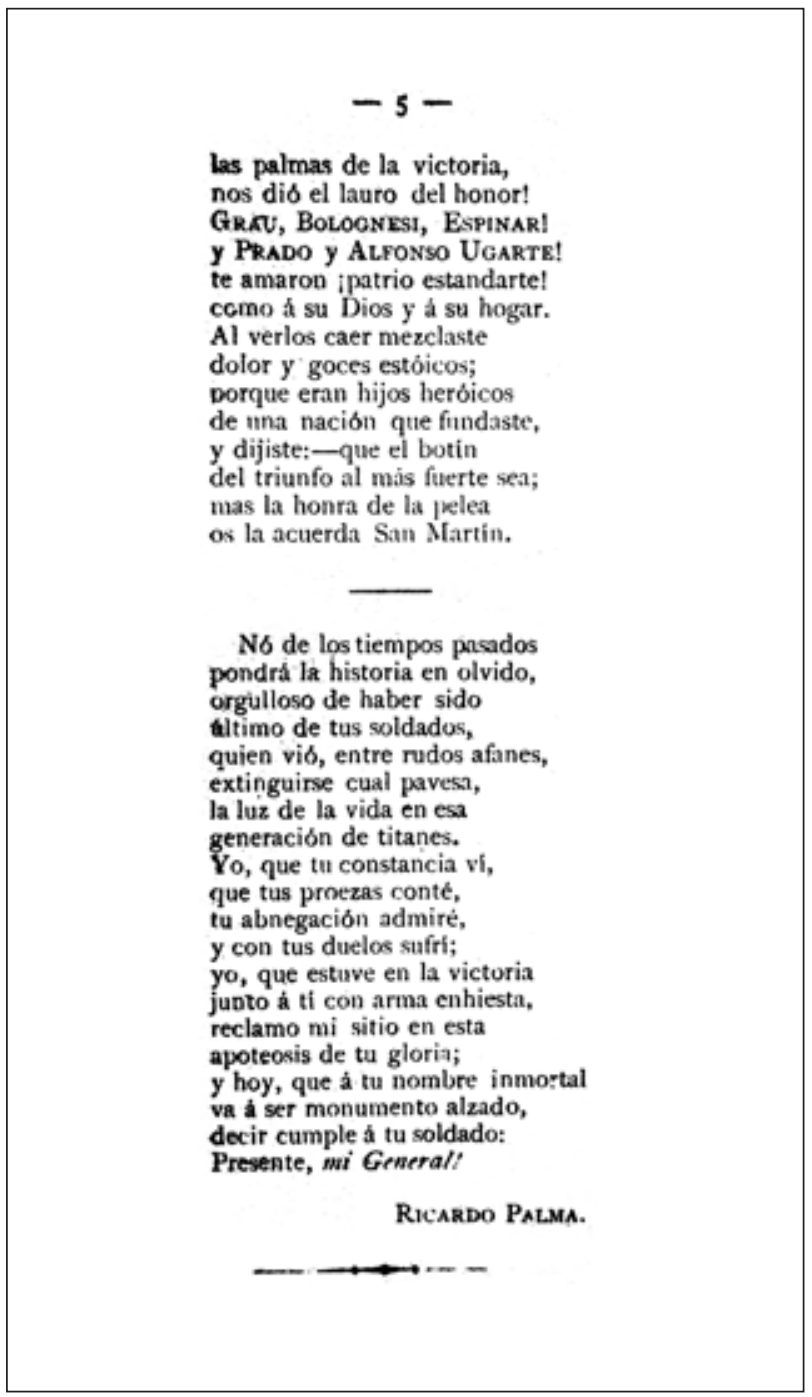

Agradecimiento: A la Sra. María Estela Reaño, bibliotecaria responsable de las Colecciones Especiales del Sistema de Bibliotecas de la PUCP, por permitirnos tomar las imágenes del poema de Ricardo Palma. 


\section{Bibliografía}

Archivo del Ministerio de Relaciones Exteriores del Perú (AMREP). Sección Legación del Perú en Chile 5-4 del 4 de setiembre de 1890 fl. 11 r.

Documentos de la legación de Perú en Chile.

Documentos de la legación de Chile en Perú

El Nacional del 28 de julio de 1890. Numero 6704, p. 2.

El Comercio del 29 de julio de 1890. №17, 166, p. 1.

Mera Ávalos, A. (2006). "Período 1876-1900". En Del Busto Duthurburu, José Antonio (director de la investigación). Historia Cronológica del Perú. Lima: Ediciones Copé, pp. 421 - 470.

Palma, R. (1890). A San Martin. Homenaje de un soldado de la patria vieja. folleto s/c [Lima] octubre de 1890, 16p.

Pérez Garay. Carlos Alberto. Liberalismo criollo. Ricardo Palma, ideología y política (1833-1919). Lima: Universidad Ricardo Palma, Editorial Universitaria, 2015.

Recibido el 6 de noviembre de 2019 Aceptado el 13 de noviembre de 2019 